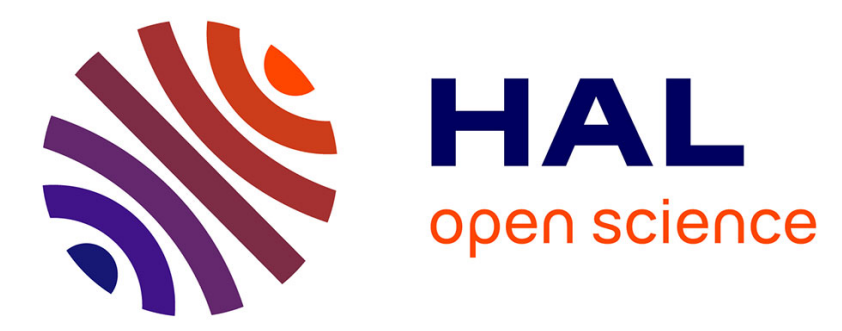

\title{
Cord serum 25-hydroxyvitamin D and risk of early childhood transient wheezing and atopic dermatitis
}

Nour Baïz, Patricia Dargent-Molina, John D. Wark, Jean-Claude Souberbielle, Isabella Annesi-Maesano

\section{- To cite this version:}

Nour Baïz, Patricia Dargent-Molina, John D. Wark, Jean-Claude Souberbielle, Isabella AnnesiMaesano. Cord serum 25-hydroxyvitamin D and risk of early childhood transient wheezing and atopic dermatitis. Journal of Allergy and Clinical Immunology, 2014, 133 (1), pp.147-53. 10.1016/j.jaci.2013.05.017 . inserm-01124405

\section{HAL Id: inserm-01124405 https://www.hal.inserm.fr/inserm-01124405}

Submitted on 6 Mar 2015

HAL is a multi-disciplinary open access archive for the deposit and dissemination of scientific research documents, whether they are published or not. The documents may come from teaching and research institutions in France or abroad, or from public or private research centers.
L'archive ouverte pluridisciplinaire HAL, est destinée au dépôt et à la diffusion de documents scientifiques de niveau recherche, publiés ou non, émanant des établissements d'enseignement et de recherche français ou étrangers, des laboratoires publics ou privés. 
1 Cord serum 25-hydroxyvitamin $D$ and risk of early childhood transient

2 wheezing and atopic dermatitis

3

4 Nour Baïz, $\mathrm{PhD}^{\mathrm{a}, \mathrm{b}}$, Patricia Dargent-Molina, $\mathrm{PhD}^{\mathrm{c}, \mathrm{d}}$, John D Wark, $\mathrm{PhD}^{\mathrm{e}}$, Jean-Claude

5 Souberbielle, $\mathrm{PhD}^{\mathrm{f}}$, Isabella Annesi-Maesano, MD, DSc, $\mathrm{PhD}^{\mathrm{a}, \mathrm{b}}$, and the EDEN Mother-

6 Child Cohort Study Group

7

$8{ }^{a}$ Inserm (Institut national de la santé et de la recherche médicale), Epidemiology of Allergic

9 and Respiratory diseases (EPAR) Department, UMR-S707, Paris, France; ${ }^{b}$ Medical School

10 Saint-Antoine, UPMC Univ6, Paris, France; ${ }^{c}$ Inserm, Epidemiological Research in Perinatal 11 Health and Women's and Child Health, UMR-S953, Villejuif, France; ${ }^{\mathrm{d}}$ University Pierre and Marie Curie, UMR-S953, Paris, France; ' Department of Medicine, The Royal Melbourne Hospital, The University of Melbourne, Parkville, Vic., Australia; ${ }^{\mathrm{f}}$ Laboratoire de physiologie, université Paris-Descartes, hôpital Necker-Enfants-Malades, Assistance Publique-Hôpitaux de Paris, Paris, France.

Corresponding author: Nour Baïz, EPAR UMR-S 707 INSERM \& UPMC Paris 6, Medical School Saint-Antoine, 27 rue Chaligny 75571 Paris CEDEX 12, France. Tel: +33 (0)1 4473 86 58. Fax: +33 (0)1 447384 54, E-mail: $\underline{\text { baiz@u707.jussieu.fr }}$ 


\section{Abstract}

2 Background: There is increasing evidence of the effect of maternal vitamin D intake during 3 pregnancy on the risk of asthma and allergic outcomes in the offspring. However, studies on 4 the relationship between cord levels of 25-hydroxyvitamin D (25[OH]D) and asthma and $5 \quad$ allergic diseases are very few.

6 Objective: Our aim was to investigate the associations between cord serum 25(OH)D levels 7 and asthma, wheezing, allergic rhinitis and atopic dermatitis in the offspring from birth to 5 8 years.

9 Methods: Cord blood samples were collected at birth and were analyzed for levels of 25(OH)D in 239 newborns from the EDEN birth cohort. The children were followed up until age 5 years by symptom ISAAC-based questionnaires (International Study of Asthma and Allergies in Childhood).

Results: The median cord serum level of $25(\mathrm{OH}) \mathrm{D}$ was $17.8 \mathrm{ng} / \mathrm{mL}$ (interquartile range: 15.1 $\mathrm{ng} / \mathrm{mL}$ ). Using multivariable-adjusted logistic regression models, a significant inverse association was observed between cord serum 25(OH)D and risk of transient early wheezing and early and late-onset atopic dermatitis, as well as atopic dermatitis by the age of 1,2, 3 and 5. We found no association between cord serum 25(OH)D levels and asthma and allergic rhinitis at 5 years of age.

Conclusions: Cord serum 25(OH)D level was inversely associated with the risk of transient early wheezing and atopic dermatitis by the age of 5 years, but no association was found with asthma and allergic rhinitis. 
1 Clinical implications: The risk of transient wheezing and atopic dermatitis in childhood is

2 inversely associated with cord $25(\mathrm{OH}) \mathrm{D}$ levels. Interventions to increase vitamin D levels in 3 utero and in early life are potential public health interventions to reduce transient wheezing 4 and atopic dermatitis in young children.

5

6 Capsule summary: Although research is required to establish the optimal level, timing and

Keywords: Vitamin D; 25-hydroxyvitamin D; Cord blood; Allergic diseases; Wheezing; Atopic dermatitis; Mother-child cohort

Abbreviations: 25(OH)D, 25-hydroxyvitamin D; EDEN, Etude des Déterminants pré et post natals du développement et de la santé de l'Enfant ; ISAAC, International Study of Asthma

and Allergies in Childhood ; OR, odds ratio ; CI, confidence interval ; SD, standard deviation.

route of exposure, recommendations for adequate vitamin D intake in pregnant women may prevent transient early childhood wheezing and atopic dermatitis. 


\section{Introduction}

Over the last decade, the prevalence of allergies and asthma in childhood has increased worldwide, particularly in westernized societies. There is increasing evidence that fetal life and early life exposures, along with associated epigenetic changes (1), are important determinants of the future development of asthma and allergies throughout life (2). Among other environmental factors, prenatal and early life dietary exposures, including vitamin D, have been suggested to play an important role in the development of allergies and asthma in childhood (3).

Vitamin D deficiency, defined as a circulating level of $<20 \mathrm{ng} / \mathrm{mL}$ of 25 hydroxyvitamin D (25(OH)D), has become a public health issue (4). It has been largely attributed to dietary, lifestyle and behavioral changes during recent decades (4), especially in Western countries. Children as well as pregnant and lactating women are identified as groups vulnerable to vitamin D deficiency (5).

While the relationship of vitamin D deficiency and rickets is well established (6), and its association with a wide variety of medical conditions including microbial infections (7), cardiovascular diseases (8), cancers (9), autoimmune diseases (10) and diabetes (11) is well documented, only more recently has the role of vitamin D deficiency and insufficiency in asthma (12-14) and allergic diseases (15) beginning in infancy or childhood (16-18) been debated. In the last couple of decades in the twentieth century and early in the twenty-first century, the vitamin D receptor has been found in a variety of cells, including keratinocytes and numerous cells of the immune system (e.g., dendritic cells, natural killer cells) (19). Several lines of evidence demonstrate the effects of vitamin D on pro-inflammatory cytokines, regulatory $\mathrm{T}$ cells, and immune responses (20).

Vitamin D is found naturally in very few dietary sources, the only really significant being fatty fish (21) and vitamin D-fortified foods. The latter are scarce in France. The main 
source of vitamin D in humans is synthesis from 7-dehydrocholesterol in the skin upon exposure to ultraviolet $\mathrm{B}$ solar radiation and conversion to a readily-measurable circulating metabolite, 25-hydroxyvitamin $\mathrm{D}(25(\mathrm{OH}) \mathrm{D})$ in the liver $(21)$. Circulating $25(\mathrm{OH}) \mathrm{D}$ is the best index of vitamin D nutritional status (21). Low intake of vitamin D and inadequate exposure to sunlight constitute the main causes of vitamin D deficiency. A number of factors may influence the cutaneous synthesis and dietary sources of vitamin D (22), especially in pregnant women (23). These factors include season of the newborn's birth, maternal vitamin D intake, body mass index, constitutive skin pigmentation, latitude, clothing, sunscreen-use, outdoors activities, age $(22,23)$ and genetic factors (24).

During pregnancy the fetus is exposed to vitamin D through cord blood supply and the ability of $25(\mathrm{OH}) \mathrm{D}$ to cross the placenta (25). Over the past 2 years, the number of studies, both cross-sectional and prospective, that have investigated the effects of maternal vitamin D intake on the inception and severity of asthma and allergies in the offspring have increased significantly. Most studies have shown that low maternal vitamin D levels (assessed by food frequency questionnaires) increase the risk for asthma (26), wheeze $(18,27,28)$ allergic rhinitis (26) and atopic dermatitis (18), but a few suggest an increased risk with high levels (29-30).

However, the majority of these studies did not use objective measures of maternal vitamin $\mathrm{D}$ status. In addition, studies examining the associations between cord blood 25(OH)D concentrations and asthma and allergic diseases (16) are still very scarce.

The purpose of the present study was to investigate whether the levels of cord serum $25(\mathrm{OH}) \mathrm{D}$, which is considered the best indicator of newborns' vitamin D status, are associated with risk of asthma, wheeze, allergic rhinitis and atopic dermatitis in offspring. Our study was conducted in the French EDEN mother-child cohort. 


\section{Methods}

\section{Study design and participants}

Mother-child pairs were recruited in the EDEN (Etude des Déterminants pré et post natals du développement et de la santé de l'Enfant) prospective Birth Cohort Study (http://eden.vjf.inserm.fr). The primary aim of the EDEN Cohort is to identify prenatal and early postnatal nutritional, environmental and social determinants associated with children's health and their normal and pathological development. Pregnant women seen for a prenatal visit at the departments of Obstetrics and Gynecology of the University Hospital of Nancy and Poitiers before their twenty-fourth week of amenorrhea were invited to participate. Enrolment started in February 2003 in Poitiers and September 2003 in Nancy; it lasted 27 months in each centre. Women with speaking and writing abilities in French, who did not suffer from type 2 diabetes diagnosed prior to pregnancy, and did not plan to deliver outside the university hospital or move out of the region within 3 years, were included in the study. Multiple pregnancies were excluded. Among eligible women, 55\% (2002 women) agreed to participate (1034 women in Nancy and 968 in Poitiers). Of the 2002 mother-child pairs included in the EDEN study, 1140 of them had complete data by the child's age of 5 years. Among the 1140 participants, measurements of cord serum $25(\mathrm{OH}) \mathrm{D}$ performed at birth were available in 239 children. The final sample for analysis consisted of 239 mother-child pairs. This sample appeared representative of the overall study population.

Women were given an appointment with a study midwife, planned to take place between 24 and 28 gestational weeks, during which an interview on behavioral factors was conducted and biological samples were collected. Further information on the mothers and their newborns, including parity, mode of delivery, newborn's sex and birth weight (measured with electronic Seca scales, Hamburg, Germany [Seca 737 in Nancy and Seca 335 in Poitiers 
with a $10 \mathrm{~g}$ precision]), gestational age and season of birth, were either collected by a questionnaire after birth or extracted from obstetrical and pediatric records. All children were equally receiving vitamin D supplementation during the first three years of life.

\section{Ethics Statement}

The ethical committees who approved the study is: Comite Consultatif pour la Protection des Personnes dans la Recherche Biomédicale, Le Kremlin-Bicêtre University hospital, and Commission Nationale de l'Informatique et des Libertés. The study was approved on 12 December 2002. Written consent was obtained from the mother for herself at the beginning of the study and from both parents for the newborn child after delivery.

\section{Cord serum 25(OH)D measurement}

Immediately after delivery, cord blood serum samples were collected by research midwives. In order to prevent any contamination with maternal blood, the cord was doubly clamped immediately after birth (vaginal delivery) or after extraction of the fetus through the uterine incision (elective caesarean section); repeatedly rinsed and venous cord blood serum was sampled between the two clamps. Blood samples were centrifuged within 24 hours of collection. The serum was separated and stored at $-80^{\circ} \mathrm{C}$. Standard operating procedures for each assay were established. Serum $25(\mathrm{OH}) \mathrm{D}$, which is considered to be the indicator of vitamin D status (31), was measured by immunochemilumiscent immunoassays performed on the LIAISON platform manufactured by DiaSorin (Sallugia, Italy). This assay measures both 25(OH)D2 and 25(OH)D3 and provides the sum of these two metabolites and does not crossreact with the $\mathrm{C} 325(\mathrm{OH}) \mathrm{D}$ epimer, which has been shown to complicate the measurement of $25(\mathrm{OH}) \mathrm{D}$ in neonates. The intra- and interassay coefficient of variation was $<10 \%$ whatever the measured concentration. 
Children were followed up from birth to age 5 years. At the age of 1,2, 3 and 5 years, parents completed questionnaires including questions on asthma, wheeze, allergic rhinitis and atopic dermatitis, based on the validated International Study of Asthma and Allergies in Childhood (ISAAC) phase-I questionnaire $(32,33)$. For each year, asthma was defined as parental report of doctor-diagnosis of asthma plus either one or more attacks of wheeze or asthma medication in the last 12 months. Wheeze was defined as present if the parents answered "yes" to the question "Has your child had wheezing or whistling in the chest in the preceding 12 months?', Parental report of wheezing has been shown to be a sensitive and specific outcome when using physician assessment as the criterion standard (34). Allergic rhinitis was defined as sneezing, nasal congestion, or rhinitis, other than with respiratory infections, accompanied by eye itching and tearing during the previous 12 months (35). And atopic dermatitis was defined as atopic dermatitis diagnosed by a doctor in the last 12 months. late-onset atopic dermatitis, e.g. atopic dermatitis up to age 2 years and thereafter.

Other Variables 
We collected information on potential confounders related to offspring health outcomes,

2 including newborn sex, birth weight, gestational age, season at birth, number of older siblings

3 at birth $(0,1-2, \geq 3)$, exclusive breastfeeding for $\geq 4$ months (yes or no), maternal age at

4 delivery ( $<25$ years, 25-34 years, or $>34$ years), pre-pregnancy maternal body mass index $\left(18.5-24.9,25.0-29.9,30.0-34.9\right.$ and $\left.35.0-39.9 \mathrm{~kg} / \mathrm{m}^{2}\right)$, maternal and paternal history of allergies (yes or no), maternal and paternal education level (primary or less, secondary, and university degree or higher), household income $(\leq 2300$ versus $>2300$ Euros per month, median income of the study population), city of residence (Nancy or Poitiers), any smoking during pregnancy (yes or no), environmental tobacco smoke exposure of the child from birth to age of 3 (yes or no), dampness in housing ( 0 - 3 years) (yes or no), and day care attendance in the first year of life (yes or no). Maternal and paternal allergic history was obtained regarding physician-diagnosed allergic diseases such asthma, rhinitis, eczema and food allergies.

\section{Statistical analyses}

The sample was described using frequencies of categorical variables and means and standard deviations of continuous variables. The characteristics of the mother-newborn pairs in our study sample $(n=239)$ were compared to the sample of mother-newborn pairs of children without measurement of cord serum 25(OH)D ( $n=901)$. We used Chi-square tests for categorical data, T-tests for normally-distributed data and Mann-Whitney U tests for skewed data.

We fitted logistic regression models to examine the associations between cord serum 25(OH)D level as a continuous variable and asthma and allergic rhinitis reported from 4 to 5 years and wheeze and atopic dermatitis by the age of 1,2, 3 and 5 years, as well as the wheezing and atopic dermatitis patterns. 
In order to identify confounding factors, bivariate analysis between potential

2 confounders and each health outcome were performed. In a first step, all variables associated with one health outcome with a $\mathrm{p}<0.30$ were retained. In a second step, confounders affecting at least $20 \%$ of the coefficient estimates of the investigated association between vitamin D and the health outcome were selected and included in the multivariate models. In addition to the inclusion of confounders based on their statistically significant association with health outcomes, we selected other adjustment variables, on the basis of their known relationship to 25(OH)D concentrations, independently of any association with exposures and regardless of whether they changed the effect estimates significantly. They included: child's sex (38), prepregnancy body mass index (39), and birthweight (40). As a result, the adjustments included: city, maternal age at delivery, maternal pre-pregnancy body mass index (BMI), any smoking during pregnancy, any passive smoke exposure during the first 3 years of life, number of siblings, household income, newborn's sex and weight, season of birth (calendar-based), and exclusive breastfeeding for $\geq 4$ months. Multiple logistic regression analysis was used to adjust for confounding factors. Estimations of crude and adjusted odds ratios (ORs) and their 95\% confidence interval (CI) of asthma, wheeze, allergic rhinitis and atopic dermatitis, at different time point, per $5 \mathrm{ng} / \mathrm{mL}$ increase of cord serum $25(\mathrm{OH}) \mathrm{D}$ concentration were made by means of logistic regression analysis.

To further explore the associations between asthma and allergic rhinitis and cord vitamin D, we examined effect modification of the association of these outcomes with cord serum $25(\mathrm{OH}) \mathrm{D}$, by stratifying the cohort according to maternal history of allergy and testing the interaction term (namely continuous $25(\mathrm{OH}) \mathrm{D}^{*}$ maternal history of allergy). All statistical analyses were performed using SAS statistical software version 9.2 (SAS Institute Inc, Cary, North Carolina). P-values $<0.05$ were considered statistically significant for all analyses. 


\section{Results}

\section{Characteristics of the mother-child pairs}

Children with both cord serum $25(\mathrm{OH}) \mathrm{D}$ data and complete questionnaires from birth to 5 years of age were included in this analysis $(n=239)$. Included children did not differ significantly from other children with complete questionnaires up to 5 years of age but without measurement of cord serum $25(\mathrm{OH}) \mathrm{D}(\mathrm{n}=901)$ with respect to all characteristics, except for season of birth and city of residence (Table I).

In our study population, no mothers reported type 2 diabetes diagnosed prior to pregnancy or chronic illnesses apart from asthma, eczema and other allergic diseases, such as rhinitis and food allergies.

\section{Health outcomes in the offspring}

By the age of 1, 2, 3 and 5 years, $24.7 \%, 32.6 \%, 35.1 \%$ and $38.9 \%$ of all children had experienced wheezing, respectively, and 10\%, 13.4\%, $14.2 \%$ and $25 \%$ had had atopic dermatitis, respectively. From age 4 to $5,8 \%$ of all children had asthma and $7.5 \%$ had allergic rhinitis. The prevalences of early transient, late-onset and persistent wheezing patterns were $28.5 \%, 11.7 \%$ and $4.2 \%$, respectively. The prevalences of early-onset and late-onset atopic dermatitis were $34.7 \%$ and $20.5 \%$, respectively.

\section{Newborns' cord serum levels of $25(\mathrm{OH}) \mathrm{D}$}

Figure 1 shows the distribution of cord blood serum $25(\mathrm{OH}) \mathrm{D}$ concentrations. The mean concentration and the interquartile range (IQR) in cord blood serum were $17.8 \mathrm{ng} / \mathrm{mL}$ and $15.1 \mathrm{ng} / \mathrm{mL}$.

Relationship of cord serum 25(OH)D and outcomes by the age of 5 years 

patterns, atopic dermatitis by the age of 1,3 and 5 years, different atopic dermatitis patterns, and asthma and allergic rhinitis at 5 years of age are presented in table II. Without adjustment, a significant inverse association was observed between cord serum 25(OH)D concentration (per $5 \mathrm{ng} / \mathrm{mL}$ increase) and the risk of early transient wheezing and atopic dermatitis by the age of 3 and 5 years and early and late-onset of atopic dermatitis. After multivariable adjustment, the previously observed significant inverse associations persisted (OR for early transient wheezing, per $5 \mathrm{ng} / \mathrm{mL}$ increase of cord serum $25(\mathrm{OH}) \mathrm{D}$ concentration: 0.67 (0.54-0.81); OR for atopic dermatitis by the age of 1,3 and 5 years : $0.84(0.71-1.00), 0.82$ (0.68-0.97), $0.75(0.63-0.88)$, respectively; and OR for early and late-onset atopic dermatitis: $0.73(0.62-0.90), 0.75(0.60-0.94)$, respectively). The adjusted inverse association along with the confidence intervals and the regression line, between cord serum 25(OH)D concentration and risk of atopic dermatitis by the age of 5 years is shown in Figure 2. The graph represents the predicted probability of atopic dermatitis by the age of 5 years for each observed value of cord serum $25(\mathrm{OH}) \mathrm{D}$ concentration in the multivariate model.

In contrast, no significant association was observed between cord serum 25(OH)D level and asthma and allergic rhinitis prevalence. To further investigate this null finding, we stratified each of these outcomes according to maternal history of allergy. In all models, cord serum 25(OH)D levels had no association according to either atopic or non-atopic maternal status (all $P>0.20)$.

\section{Discussion}

\section{Main findings}

In this prospective birth cohort study of French mother-child pairs, we found that cord serum concentration of $25(\mathrm{OH}) \mathrm{D}$ was negatively associated with early transient wheezing, 
atopic dermatitis by the age of 1, 3 and 5 and early and late-onset atopic dermatitis. However, cord serum $25(\mathrm{OH}) \mathrm{D}$ levels were not associated with risk of other wheezing phenotypes, asthma and allergic rhinitis at 5 years of age.

\section{In literature}

To date, there is sparse information on vitamin D status and wheezing and atopic dermatitis. The few studies that have investigated the association between maternal vitamin D status and risk of wheezing (41) and atopic dermatitis (18) in childhood are limited by the fact that vitamin D intake was based only on food frequency questionnaires $(18,28)$. Although such methods have been validated and are representative of intake over a period of time, most of these observational studies did not have direct serological measures of $25(\mathrm{OH}) \mathrm{D}$ levels to accurately confirm vitamin D status. However, all studies adjusted for total energy intake and for other nutrients associated with healthy diets.

Additionally, a study in 2008 found that vitamin D supplementation significantly improved skin symptoms in children with winter-related atopic dermatitis (42). And in adults, Oren et al. (43) also found a protective effect of vitamin D on atopic dermatitis. These results raise interesting questions about the potential role of vitamin $\mathrm{D}$ in the pathogenesis of atopic dermatitis.

Regarding the relationship between early transient wheezing and vitamin D deficit, Martinez et al. (37) found evidence that, in most cases, infant wheeze is a transient condition, not associated with increased risk of asthma or allergies later in life. In transient wheezer infants, a reduced airway caliber seems to be the predisposing factor to wheeze in association with viral infections. In our study, the inverse association between cord serum $25(\mathrm{OH}) \mathrm{D}$ 
1 levels and early transient wheezing is consistent with Camargo et al. findings (16) of an

2 inverse relationship between cord blood 25(OH)D levels and respiratory infections.

3

4

\section{Potential mechanisms}

Cord vitamin D may play a protective role against transient wheezing through its effects on the immune function $(44,45)$. The molecular effects of vitamin D in the skin have been well documented in experimental studies. Vitamin D receptor (VDR) expression in the skin was first confirmed after rats injected with radio-labeled 1,25-dihydroxyvitamin D $(1,25(\mathrm{OH}) 2 \mathrm{D})$, the active form of $25(\mathrm{OH}) \mathrm{D}$, demonstrated radioactivity concentrated in the nuclei of the epidermis along with a variety of other tissues (46). 1,25(OH) enhances keratinocyte differentiation, as well as have either stimulatory or suppressive effects on keratinocyte growth that is concentration dependent (47).

In addition, there is evidence to suggest that vitamin $\mathrm{D}$ decreases inflammatory responses in epidermal keratinocytes (48-50). In vitro treatment of dendritic cells (DCs) with $1,25(\mathrm{OH}) 2 \mathrm{D}$ or vitamin D analogues led to decreased IL-12 and enhanced IL-10. These cytokine effects, along with inhibitory effects on DC maturation, promote tolerogenic properties and suppressor $\mathrm{T}$ cell induction (51). A short treatment course of 1,25(OH)2D in mice induced tolerogenic DCs and increased regulatory T cells (52). As a result, vitamin D may promote regulatory $\mathrm{T}$ cells that are known to play an important role in the prevention of atopic dermatitis development (53) by playing a pivotal role in immune suppression and being crucial to the control of allergic responses.

Vitamin D also has a beneficial effect on the permeability barrier in the epidermis. Bikle et $a l$. examined mice null for the expression of $25(\mathrm{OH}) \mathrm{D}-1 \alpha$-hydroxylase. Lower levels of multiple proteins necessary for formation of the stratum corneum, including filaggrin, were observed in the null mice compared to the wild type controls (54). Following skin barrier 
disruption, null mice had a significantly delayed barrier recovery compared to wild type mice (54).

Another potential role for vitamin D is suggested by the work of Schauber et al. (55), who found that $1,25(\mathrm{OH}) 2 \mathrm{D}$ enables keratinocytes to recognize and respond to microbes through action on the Toll-like receptor 2 and leads to upregulation of cathelicidin, an antimicrobial peptide. As a result, vitamin D may promote the production of antimicrobial peptides that have the ability to enhance immunity and protect skin from bacterial infections.

Consequently, given the fact that the pathogenesis of atopic dermatitis involves both epidermal barrier and immunologic dysfunction, vitamin D may have a protective role against atopic dermatitis and the development of a variety of other skin disorders as well.

\section{Strengths and limitations}

First, this is one of the few birth cohort studies to have measured vitamin D levels in cord blood as opposed to estimating infant levels based on vitamin D levels in pregnant women (30) or maternal intake of vitamin D during pregnancy $(18,26,28,41)$. Additionally, newborns's vitamin D status was assessed by measuring serum levels of 25-hydroxyvitamin $\mathrm{D}$, which is considered the best circulating biomarker of vitamin $\mathrm{D}$ metabolic status. The analyses were performed on the continuous $25(\mathrm{OH}) \mathrm{D}$ variable, since the often used categorization of vitamin D levels is still arbitrary and without consensus. An additional strength of our prospective investigation consists in the robustness of the results as children were drawn from a cohort and their parents were able to provide information on possible confounders, thus diminishing the probability of biased or confounded results. In addition, we collected outcome data at different ages, providing more robust measures of potential health effects than single time-point outcomes could provide. The definition of health outcomes was based on the validated ISAAC questions. 

obtained from parental report through self-administered questionnaires, which could result in misclassification. We could not obtain vitamin D data from all eligible newborns with complete information at age 5 years, which may have introduced selection bias. Because of the sample size of our study, although the change-in-estimate $(\mathrm{CE})$ criterion $\geq 10 \%$ is a conventional one (56), a more conservative criterion $\geq 20 \%$ was used in order to select potential confounders. In addition, the absence of significant associations between asthma, allergic rhinitis and $25(\mathrm{OH}) \mathrm{D}$ concentrations may be due to the low prevalences of these outcomes, consequently limiting the power to detect a relationship between $25(\mathrm{OH}) \mathrm{D}$ and the outcome. An often-cited limitation of serologic studies is the reliance on a single $25(\mathrm{OH}) \mathrm{D}$ measurement per subject. It would have been interesting to measure serum $25(\mathrm{OH}) \mathrm{D}$ levels during childhood. The half-life of serum 25(OH)D is approximately 2 to 3 weeks (57), which suggests that the measured concentrations reflect maternal-fetal status during the final months of pregnancy and first months of life. All children in our study were receiving vitamin D supplement during the first three years of life, so difference between children vitamin D levels may depend on diet along with food diversification and on sun-related behaviors, despite heightened awareness of the carcinogenic effect of sun exposure (58). Finally, subjects were followed only to age 5 years, at which age asthma may be evolving from being infectionrelated to being predominantly related to allergy. Similarly, wheezing in the preschool years is not necessarily indicative of allergic disease as we know that wheeze may be induced by viral infection (59).

\section{Conclusion}

In summary, our data indicate an inverse association between cord serum $25(\mathrm{OH}) \mathrm{D}$ levels and the risk of early transient wheezing and atopic dermatitis in young children. In 
1 contrast, we found no apparent association between cord serum 25(OH)D concentrations and

2 other wheezing phenotypes, asthma and allergic rhinitis at 5 years of age.

If these associations are causal, interventions to increase vitamin D levels in utero and

4 in early life could reduce the risk of transient wheezing and atopic dermatitis in early

5 childhood. Increased exposure to sunlight and increased intake of foods high in vitamin D

6 (not necessarily supplementation) in both pregnant women and infants are potential public

7 health interventions.

In light of recent findings on the role of vitamin $\mathrm{D}$, and its effects on asthma and

9 allergic diseases, studies of vitamin D may enhance the understanding, prevention and treatment of these increasingly common conditions in childhood. Further research is required to establish the optimal level (or range) of vitamin D that decreases both the risk for

12 development and severity of these disorders, but also the timing and route of exposure to vitamin D. 
1. Bollati V, Baccarelli A. Environmental epigenetics. Heredity (Edinb). 2010 $\mathrm{Jul} ; 105(1): 105-12$.

2. Gillman MW. Developmental origins of health and disease. N Engl J Med. 2005 Oct 27;353(17):1848-50.

3. Robison R, Kumar R. The effect of prenatal and postnatal dietary exposures on childhood development of atopic disease. Curr Opin Allergy Clin Immunol. 2010 Apr;10(2):139-44.

4. Holick MF. Vitamin D deficiency. N Engl J Med. 2007 Jul 19;357(3):266-81.

5. Mulligan ML, Felton SK, Riek AE, Bernal-Mizrachi C. Implications of vitamin D deficiency in pregnancy and lactation. Am J Obstet Gynecol. 2010 May;202(5):429 e1-9.

6. Thandrayen K, Pettifor JM. Maternal vitamin D status: implications for the development of infantile nutritional rickets. Endocrinol Metab Clin North Am. 2010 Jun;39(2):303-20, table of contents.

7. Ginde AA, Mansbach JM, Camargo CA, Jr. Association between serum 25hydroxyvitamin D level and upper respiratory tract infection in the Third National Health and Nutrition Examination Survey. Arch Intern Med. 2009 Feb 23;169(4):384-90.

8. Kim DH, Sabour S, Sagar UN, Adams S, Whellan DJ. Prevalence of hypovitaminosis $\mathrm{D}$ in cardiovascular diseases (from the National Health and Nutrition Examination Survey 2001 to 2004). Am J Cardiol. 2008 Dec 1;102(11):1540-4.

9. Trump DL, Deeb KK, Johnson CS. Vitamin D: considerations in the continued development as an agent for cancer prevention and therapy. Cancer J. 2010 Jan-Feb;16(1):1-9. 10. Kinder B, Hagaman, JT. Could combating vitamin D deficiency reduce the incidence of autoimmune disease? . Expert Rev Clin Immunol. 2011;7(3):255-7.

11. Ozfirat Z, Chowdhury TA. Vitamin D deficiency and type 2 diabetes. Postgrad Med J. $2010 \mathrm{Jan} ; 86(1011): 18-25$; quiz 4.

12. Lange NE, Litonjua A, Hawrylowicz CM, Weiss S. Vitamin D, the immune system and asthma. Expert Rev Clin Immunol. 2009 Nov;5(6):693-702.

13. Mak G, Hanania NA. Vitamin D and asthma. Curr Opin Pulm Med. 2011 Jan;17(1):15.

14. Brehm JM, Schuemann B, Fuhlbrigge AL, Hollis BW, Strunk RC, Zeiger RS, et al. Serum vitamin D levels and severe asthma exacerbations in the Childhood Asthma Management Program study. J Allergy Clin Immunol. 2010 Jul;126(1):52-8 e5.

15. Annesi-Maesano I. Perinatal events, vitamin D, and the development of allergy. Pediatr Res. 2002 Jul;52(1):3-5.

16. Camargo CA, Jr., Ingham T, Wickens K, Thadhani R, Silvers KM, Epton MJ, et al. Cord-blood 25-hydroxyvitamin D levels and risk of respiratory infection, wheezing, and asthma. Pediatrics. $2011 \mathrm{Jan} ; 127(1)$ :e180-7.

17. Bozzetto S, Carraro S, Giordano G, Boner A, Baraldi E. Asthma, allergy and respiratory infections: the vitamin D hypothesis. Allergy. 2011 Sep 21.

18. Miyake Y, Sasaki S, Tanaka K, Hirota Y. Dairy food, calcium and vitamin D intake in pregnancy, and wheeze and eczema in infants. Eur Respir J. 2010 Jun;35(6):1228-34.

19. Rudzki E, Samochocki Z, Rebandel P, Saciuk E, Galecki W, Raczka A, et al. Frequency and significance of the major and minor features of Hanifin and Rajka among patients with atopic dermatitis. Dermatology. 1994;189(1):41-6.

20. Hewison M. An update on vitamin D and human immunity. Clin Endocrinol (Oxf). 2012 Mar;76(3):315-25.

48 21. Brown AJ, Dusso A, Slatopolsky E. Vitamin D. Am J Physiol. 1999 Aug;277(2 Pt

$49 \quad 2): F 157-75$. 
22. Tsiaras WG, Weinstock MA. Factors influencing vitamin D status. Acta Derm Venereol. 2011 Mar;91(2):115-24.

23. Dror DK, King JC, Durand DJ, Allen LH. Association of modifiable and nonmodifiable factors with vitamin D status in pregnant women and neonates in Oakland, CA. J Am Diet Assoc. 2011 Jan;111(1):111-6.

24. Wang TJ, Zhang F, Richards JB, Kestenbaum B, van Meurs JB, Berry D, et al. Common genetic determinants of vitamin D insufficiency: a genome-wide association study. Lancet. 2010 Jul 17 2010;376(9736):180-8.

25. Salle BL, Delvin EE, Lapillonne A, Bishop NJ, Glorieux FH. Perinatal metabolism of vitamin D. Am J Clin Nutr. 2000 May;71(5 Suppl):1317S-24S.

26. Erkkola M, Kaila M, Nwaru BI, Kronberg-Kippila C, Ahonen S, Nevalainen J, et al. Maternal vitamin D intake during pregnancy is inversely associated with asthma and allergic rhinitis in 5-year-old children. Clin Exp Allergy. 2009 Jun;39(6):875-82.

27. Camargo CAJR-S, S.L.; Litonjua, A.A.; Rich-Edwards, J.W.; Weiss, S.T.; Gold, D.R.; Kleinman, K.; Gillman, M.W. Prospective study of maternal intake of vitamin D during pregnancy and risk of wheezing illness in children at age 2 years. J Allergy Clin Immunol 2006;117:721-2.

28. Camargo CA, Jr., Rifas-Shiman SL, Litonjua AA, Rich-Edwards JW, Weiss ST, Gold $\mathrm{DR}$, et al. Maternal intake of vitamin D during pregnancy and risk of recurrent wheeze in children at 3 y of age. Am J Clin Nutr. 2007 Mar;85(3):788-95.

29. Hypponen E, Sovio U, Wjst M, Patel S, Pekkanen J, Hartikainen AL, et al. Infant vitamin d supplementation and allergic conditions in adulthood: northern Finland birth cohort 1966. Ann N Y Acad Sci. 2004 Dec;1037:84-95.

30. Gale CR, Robinson SM, Harvey NC, Javaid MK, Jiang B, Martyn CN, et al. Maternal vitamin D status during pregnancy and child outcomes. Eur J Clin Nutr. 2008 Jan;62(1):6877.

31. Holick MF. Vitamin D status: measurement, interpretation, and clinical application. Ann Epidemiol. 2009 Feb;19(2):73-8.

32. Worldwide variations in the prevalence of asthma symptoms: the International Study of Asthma and Allergies in Childhood (ISAAC). Eur Respir J. 1998 Aug;12(2):315-35.

33. Williams H, Robertson C, Stewart A, Ait-Khaled N, Anabwani G, Anderson R, et al. Worldwide variations in the prevalence of symptoms of atopic eczema in the International Study of Asthma and Allergies in Childhood. J Allergy Clin Immunol. 1999 Jan;103(1 Pt 1):125-38.

34. Chong Neto HJ, Rosario N, Dela Bianca AC, Sole D, Mallol J. Validation of a questionnaire for epidemiologic studies of wheezing in infants. Pediatr Allergy Immunol. $2007 \mathrm{Feb} ; 18(1): 86-7$.

35. Asher MI, Keil U, Anderson HR, Beasley R, Crane J, Martinez F, et al. International Study of Asthma and Allergies in Childhood (ISAAC): rationale and methods. Eur Respir J. 1995 Mar;8(3):483-91.

36. Expert Panel Report 3 (EPR-3): Guidelines for the Diagnosis and Management of Asthma-Summary Report 2007. J Allergy Clin Immunol. 2007 Nov;120(5 Suppl):S94-138.

37. Martinez FD, Wright AL, Taussig LM, Holberg CJ, Halonen M, Morgan WJ. Asthma and wheezing in the first six years of life. The Group Health Medical Associates. N Engl J Med. 1995 Jan 19;332(3):133-8.

38. Almqvist C, Worm M, Leynaert B. Impact of gender on asthma in childhood and adolescence: a GA2LEN review. Allergy. 2008 Jan;63(1):47-57.

39. Patel SP, Rodriguez A, Little MP, Elliott P, Pekkanen J, Hartikainen AL, et al. Associations between pre-pregnancy obesity and asthma symptoms in adolescents. J Epidemiol Community Health. 2011 Aug 15. 
40. Agosti M, Vegni C, Gangi S, Benedetti V, Marini A. Allergic manifestations in very low-birthweight infants: a 6-year follow-up. Acta Paediatr Suppl. 2003 Sep;91(441):44-7.

41. Devereux G, Litonjua AA, Turner SW, Craig LC, McNeill G, Martindale S, et al. Maternal vitamin D intake during pregnancy and early childhood wheezing. Am J Clin Nutr. 2007 Mar;85(3):853-9.

42. Sidbury R, Sullivan AF, Thadhani RI, Camargo CA, Jr. Randomized controlled trial of vitamin D supplementation for winter-related atopic dermatitis in Boston: a pilot study. $\mathrm{Br} \mathrm{J}$ Dermatol. 2008 Jul;159(1):245-7.

43. Oren E, Banerji A, Camargo CA, Jr. Vitamin D and atopic disorders in an obese population screened for vitamin D deficiency. J Allergy Clin Immunol. 2008 Feb;121(2):5334.

44. Liu PT, Stenger S, Li H, Wenzel L, Tan BH, Krutzik SR, et al. Toll-like receptor triggering of a vitamin D-mediated human antimicrobial response. Science. 2006 Mar 24;311(5768):1770-3.

45. Adams JS, Hewison M. Unexpected actions of vitamin D: new perspectives on the regulation of innate and adaptive immunity. Nat Clin Pract Endocrinol Metab. 2008 Feb;4(2):80-90.

46. Stumpf WE, Sar M, Reid FA, Tanaka Y, DeLuca HF. Target cells for 1,25dihydroxyvitamin D3 in intestinal tract, stomach, kidney, skin, pituitary, and parathyroid. Science. 1979 Dec 7;206(4423):1188-90.

47. Gurlek A, Pittelkow MR, Kumar R. Modulation of growth factor/cytokine synthesis and signaling by 1alpha,25-dihydroxyvitamin $\mathrm{D}(3)$ : implications in cell growth and differentiation. Endocr Rev. 2002 Dec;23(6):763-86.

48. Zhang JZ, Maruyama K, Ono I, Iwatsuki K, Kaneko F. Regulatory effects of 1,25dihydroxyvitamin D3 and a novel vitamin D3 analogue MC903 on secretion of interleukin-1 alpha (IL-1 alpha) and IL-8 by normal human keratinocytes and a human squamous cell carcinoma cell line (HSC-1). J Dermatol Sci. 1994 Feb;7(1):24-31.

49. Komine M, Watabe Y, Shimaoka S, Sato F, Kake K, Nishina H, et al. The action of a novel vitamin D3 analogue, OCT, on immunomodulatory function of keratinocytes and lymphocytes. Arch Dermatol Res. 1999 Sep;291(9):500-6.

50. Fukuoka M, Ogino Y, Sato H, Ohta T, Komoriya K, Nishioka K, et al. RANTES expression in psoriatic skin, and regulation of RANTES and IL-8 production in cultured epidermal keratinocytes by active vitamin D3 (tacalcitol). Br J Dermatol. 1998 Jan;138(1):6370.

51. Adorini L, Penna G, Giarratana N, Roncari A, Amuchastegui S, Daniel KC, et al. Dendritic cells as key targets for immunomodulation by Vitamin D receptor ligands. J Steroid Biochem Mol Biol. 2004 May;89-90(1-5):437-41.

52. Gregori S, Casorati M, Amuchastegui S, Smiroldo S, Davalli AM, Adorini L. Regulatory $\mathrm{T}$ cells induced by 1 alpha,25-dihydroxyvitamin D3 and mycophenolate mofetil treatment mediate transplantation tolerance. J Immunol. 2001 Aug 15;167(4):1945-53.

53. Agrawal R, Wisniewski JA, Woodfolk JA. The role of regulatory $\mathrm{T}$ cells in atopic dermatitis. Curr Probl Dermatol. 2011;41:112-24.

54. Bikle DD, Pillai S, Gee E, Hincenbergs M. Regulation of 1,25-dihydroxyvitamin D production in human keratinocytes by interferon-gamma. Endocrinology. 1989 Feb;124(2):655-60.

55. Schauber J, Gallo RL. Antimicrobial peptides and the skin immune defense system. J Allergy Clin Immunol. 2008 Aug;122(2):261-6.

56. Tong IS, Lu Y. Identification of confounders in the assessment of the relationship between lead exposure and child development. Ann Epidemiol. 2001 Jan;11(1):38-45. 
1 57. Haddad JG, Jr., Rojanasathit S. Acute administration of 25-hydroxycholecalciferol in 2 man. J Clin Endocrinol Metab. 1976 Feb;42(2):284-90.

3 58. Wright CY, Reeder AI, Bodeker GE, Gray A, Cox B. Solar UVR exposure, concurrent 4 activities and sun-protective practices among primary schoolchildren. Photochem Photobiol. 52007 May-Jun;83(3):749-58.

6 59. Jartti T, Kuusipalo H, Vuorinen T, Soderlund-Venermo M, Allander T, Waris M, et al. 7 Allergic sensitization is associated with rhinovirus-, but not other virus-, induced wheezing in 8 children. Pediatr Allergy Immunol. 2010 Nov;21(7):1008-14. 
TABLE I. Comparison of basic characteristics of mother-newborn pairs with $(\mathrm{n}=239)$ and without $(\mathrm{n}=901)$ measurement of cord serum $25(\mathrm{OH}) \mathrm{D}$

\begin{tabular}{|c|c|c|c|}
\hline & $\begin{array}{c}\text { Study sample with } \\
\text { measurement } \\
(n=239)\end{array}$ & $\begin{array}{c}\text { Sample without } \\
\text { measurement } \\
(\mathrm{n}=901)\end{array}$ & $P$-value \\
\hline \multicolumn{4}{|l|}{ City, \% } \\
\hline Poitiers & 47.7 & 57.3 & \\
\hline Nancy & 52.3 & 42.7 & 0.008 \\
\hline Maternal age, Mean $\pm \mathrm{SD}^{*}$ (years) & $30.8 \pm 4.6$ & $30.5 \pm 4.7$ & 0.6 \\
\hline$<25, \%$ & 9.2 & 11.6 & \\
\hline $25-34, \%$ & 69.5 & 71.1 & \\
\hline$>34, \%$ & 21.3 & 17.4 & 0.3 \\
\hline BMI, Mean \pm SD $\left(\mathrm{kg} / \mathrm{m}^{2}\right)$ & $26.4 \pm 4.4$ & $26.3 \pm 4.5$ & 0.6 \\
\hline Normal, $\%$ & 46.8 & 45.9 & \\
\hline Overweight, $\%$ & 36.7 & 37.1 & \\
\hline Moderate obesity, $\%$ & 11.4 & 11.6 & \\
\hline Severe obesity, $\%$ & 5.1 & 5.4 & 0.9 \\
\hline Maternal allergies, \% & 31.4 & 31.0 & 0.9 \\
\hline Paternal allergies, \% & 23.0 & 22.3 & 0.8 \\
\hline \multicolumn{4}{|l|}{ Maternal educational level, \% } \\
\hline Primary school or less & 3.3 & 4.9 & \\
\hline Secondary school & 56.2 & 59.3 & \\
\hline University degree or higher & 40.5 & 35.9 & 0.1 \\
\hline \multicolumn{4}{|l|}{ Paternal educational level, \% } \\
\hline Primary school or less & 8.2 & 7.2 & \\
\hline Secondary school & 64.3 & 65.0 & \\
\hline University degree or higher & 27.5 & 27.8 & 0.7 \\
\hline Smoking during pregnancy (active, passive), \% & 31.9 & 31.8 & 0.5 \\
\hline $\begin{array}{l}\text { Environmental tobacco smoke exposure of the } \\
\text { child ( } 0-3 \text { years }) \%\end{array}$ & 44.8 & 48.5 & 0.3 \\
\hline Dampness in housing ( $(0-3$ years), $\%$ & 5.9 & 7.8 & 0.3 \\
\hline Attending daycare (0-1 years), \% & 15.9 & 12.0 & 0.1 \\
\hline \multicolumn{4}{|l|}{ Household income (Euros), \% } \\
\hline$\leq 2300$ & 36.0 & 43.0 & \\
\hline$>2300$ & 64.0 & 57.0 & 0.06 \\
\hline \multicolumn{4}{|l|}{ Older siblings, \% } \\
\hline 0 & 45.6 & 49.0 & \\
\hline $1-2$ & 48.1 & 47.5 & \\
\hline$\geq 3$ & 6.3 & 3.6 & 0.1 \\
\hline Birth weight, Mean $(\mathrm{kg}) \pm \mathrm{SD}$ & $3.4 \pm 0.5$ & $3.3 \pm 0.5$ & 0.06 \\
\hline Gestational age at birth, Mean (weeks) \pm SD & $39.5 \pm 1.5$ & $39.2 \pm 1.8$ & 0.3 \\
\hline \multicolumn{4}{|l|}{ Sex of the newborn, \% } \\
\hline Female & 41.8 & 48.0 & \\
\hline Male & 58.2 & 52.1 & 0.1 \\
\hline \multicolumn{4}{|l|}{ Season of birth, \% } \\
\hline Summer & 23.4 & 26.9 & \\
\hline Autumn & 20.5 & 23.1 & \\
\hline Winter & 16.7 & 23.8 & \\
\hline Spring & 39.3 & 23.3 & 0.0008 \\
\hline Exclusively breastfed for $\geq 4$ months, $\%$ & 16.3 & 14.8 & 0.6 \\
\hline
\end{tabular}


1 TABLE II. Association between cord blood 25(OH)D levels (per $5 \mathrm{ng} / \mathrm{mL}$ increase) and risk 2 of wheeze and atopic dermatitis outcomes, and asthma and allergic rhinitis $(\mathrm{n}=239)$

\begin{tabular}{|c|c|c|}
\hline \multirow[b]{2}{*}{ Outcome } & \multicolumn{2}{|c|}{ OR $(95 \% \mathrm{CI}) *$} \\
\hline & Unadjusted & Adjusted $\uparrow$ \\
\hline \multicolumn{3}{|l|}{ Wheeze } \\
\hline Early transient & $0.77(0.69-0.95), P \$=0.01$ & $0.67(0.54-0.81), P=0.0002$ \\
\hline Late-onset & $0.94(0.77-1.16), P=0.58$ & $0.86(0.67-1.11), P=0.24$ \\
\hline Persistent & $1.10(0.70-0.95), P=0.50$ & $1.15(0.79-1.691), P=0.46$ \\
\hline \multicolumn{3}{|l|}{ Atopic dermatitis } \\
\hline By the age of 1 & $0.88(0.76-1.00), P=0.08$ & $0.84(0.71-1.00), P=0.05$ \\
\hline By the age of 2 & $0.86(0.77-1.00), P=0.05$ & $0.82(0.70-0.95), P=0.02$ \\
\hline By the age of 3 & $0.87(0.76-1.00), P=0.05$ & $0.82(0.68-0.97), P=0.02$ \\
\hline By the age of 5 & $0.82(0.71-0.91), P=0.003$ & $0.75(0.63-0.88), P=0.0005$ \\
\hline Early-onset & $0.82(0.70-0.95), P=0.01$ & $0.73(0.62-0.90), P=0.002$ \\
\hline Late-onset & $0.82(0.68-0.98), P=0.03$ & $0.75(0.60-0.94), P=0.01$ \\
\hline Asthma at 5 & $1.09(0.87-1.38), P=0.42$ & $1.07(0.78-1.45), P=0.69$ \\
\hline Allergic rhinitis at 5 & $1.06(0.84-1.34), P=0.62$ & $0.99(0.72-1.38), P=0.98$ \\
\hline
\end{tabular}




\section{Figure legends}

FIG 1. Distribution of vitamin D levels in cord blood (ng/mL). Vitamin D levels are indicated on the $\mathrm{x}$-axis and percentages of newborns are indicated on the $\mathrm{y}$-axis. IQR = interquartile range. To convert ng/mL 25-hydroxyvitamin $\mathrm{D}$ to $\mathrm{nmol} / \mathrm{L}$, multiply $\mathrm{ng} / \mathrm{mL}$ by 2.496 .

2 FIG 2. Adjusted associations between cord serum 25(OH)D levels and predicted probabilities 3 of atopic dermatitis by age of 5 years. 